\title{
A Small-Scale Adventure Learning Activity and its Implications for Higher Education Practice and Research
}

George Veletsianos

University of Texas

\section{Author Note}

Data collection for this research was conducted while the author was affiliated with the University of Manchester, UK.

\begin{abstract}
In this paper, I discuss the implementation of a small-scale Adventure Learning project in a higher education classroom. Data used to evaluate the Adventure Learning project indicates that the learner experience was engaging, meaningful, fun, and challenging. Suggestions for future practice and research include a call to rethink education in terms of pedagogy, social technologies, creative curricula, authentic learning, and narrative. Higher education learning experiences should foster participation and interaction and envision integrative approaches to learning that not only solve problems but also reconsider the kinds of experiences that we offer to learners.
\end{abstract}

Keywords: adventure learning; pedagogy; social technologies; higher education; narrative 


\section{A Small-Scale Adventure Learning Activity and its Implications for Higher Education Practice and Research}

In this paper, I examine how instructors and designers can enhance educational practice by discussing a small-scale Adventure Learning activity designed within a higher education curriculum. To this date, Adventure Learning "has only been implemented as a distance education approach in the K-12 environment in the context of large-scale projects focusing on socio-scientific issues of global concern" (Veletsianos \& Kleanthous, 2009, pp. 97). This paper fills a gap in research and practice by exploring the viability of Adventure Learning for smallscale interventions in higher education settings.

Technological innovation has transformed diverse aspects of modern society including business, healthcare, and transport. Widespread access to the Internet, the availability and reduced costs of broadband, low cost of mobile devices, and familial and work commitments, have made online learning accessible and desirable to increasing numbers of students over the last ten years. For instance, enrolment in at least one online course as a percentage of total enrolment for higher education students in the United States has increased from $9.2 \%$ in 2002 to 25.3\% in 2008 (Allen \& Seaman, 2010). In other words, about 1 in 4 higher education students are now taking at least one online course.

While technological innovation has enhanced access to education and provided opportunities for change, its impact on learning outcomes and teaching methods has been mixed (Bednarz \& van der Schee, 2006; Cuban, 2001; Schrum et al., 2007; Van Hover et al., 2006). The nature of education has remained virtually the same, with new technologies utilized in passive and familiar ways. For instance, Herrington et. al. (2009), in discussing the use of mobile technologies in education, note:

Despite the significant potential of mobile technologies to be employed as powerful learning tools in higher education, their current use appears to be predominantly within a didactic, teacher-centred paradigm, rather than a more constructivist environment...current use of mobile devices in higher education (essentially content delivery) is pedagogically conservative and regressive. Their adoption is following a typical pattern where educators revert to old pedagogies as they come to terms with the capabilities of new technologies. (p. 2)

Indeed, the greatest enhancement that technology seems to have provided for education has been in terms of efficiency while effectiveness and engagement seem to have suffered as a result of the "strong pressures [that exist] to produce mediocre instructional products based on templates and preexisting content” (Wilson, Parrish, \& Veletsianos, 2008, p. 42).

I proceed by discussing the Adventure Learning approach to education, and highlighting how technology can become an integral constituent of education as opposed to a mere addition to the learning experience and teaching practice. Next, I present a higher education activity designed with these ideas in mind, and in the process, highlight the important links between pedagogy, social media, curricula, narrative, and participation in authentic practice. I conclude by proposing that the purposeful integration of these five areas can accelerate transformation of educational practice. 


\section{Adventure Learning}

Adventure Learning (AL) provides learners with opportunities to explore real-world issues through collaborative, authentic, and inquiry-based learning experiences within hybrid learning environments (Doering, 2006; Doering \& Veletsianos, 2008, Veletsianos \& Kleanthous, 2009). However, few Adventure Learning projects have been grounded on a clear theoretical and research framework (Doering, 2006). The one Adventure Learning project supported by theory and long-term research focuses on a multidisciplinary K-12 program entitled GoNorth! (Doering, 2007; Doering \& Veletsianos, 2008; Veletsianos \& Doering, 2010). This project follows the same storyline each year: a team of explorers and educators traverse an Arctic region of the world on a dog sledding expedition to engage learners with a freely available inquiry-based curriculum that explores socio-scientific issues of global concern (e.g., global warming). For example, the 2006 curriculum and activity guide is available here. Students can follow the expedition and participate in the learning experience via an online learning environment which is enhanced by electronic media sent from the trail, media sent from the trail, such as audio Artifact 1) and video (Artifact 2) artifacts.

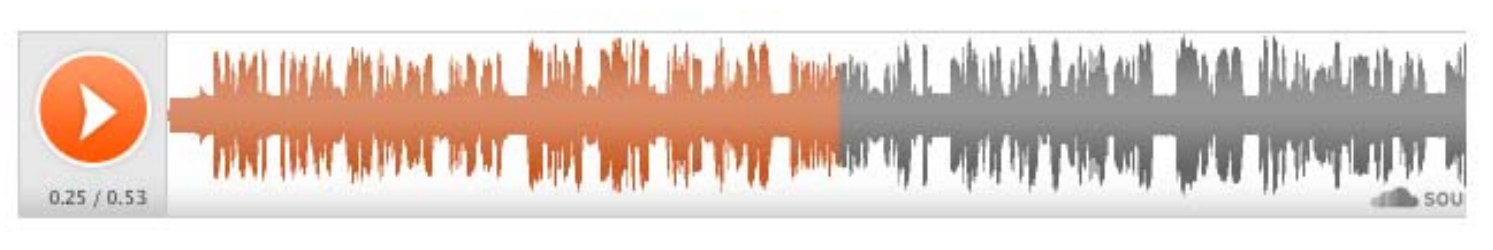

Artifact 1. Complete White. April 28, 2010 audio update from the trail.

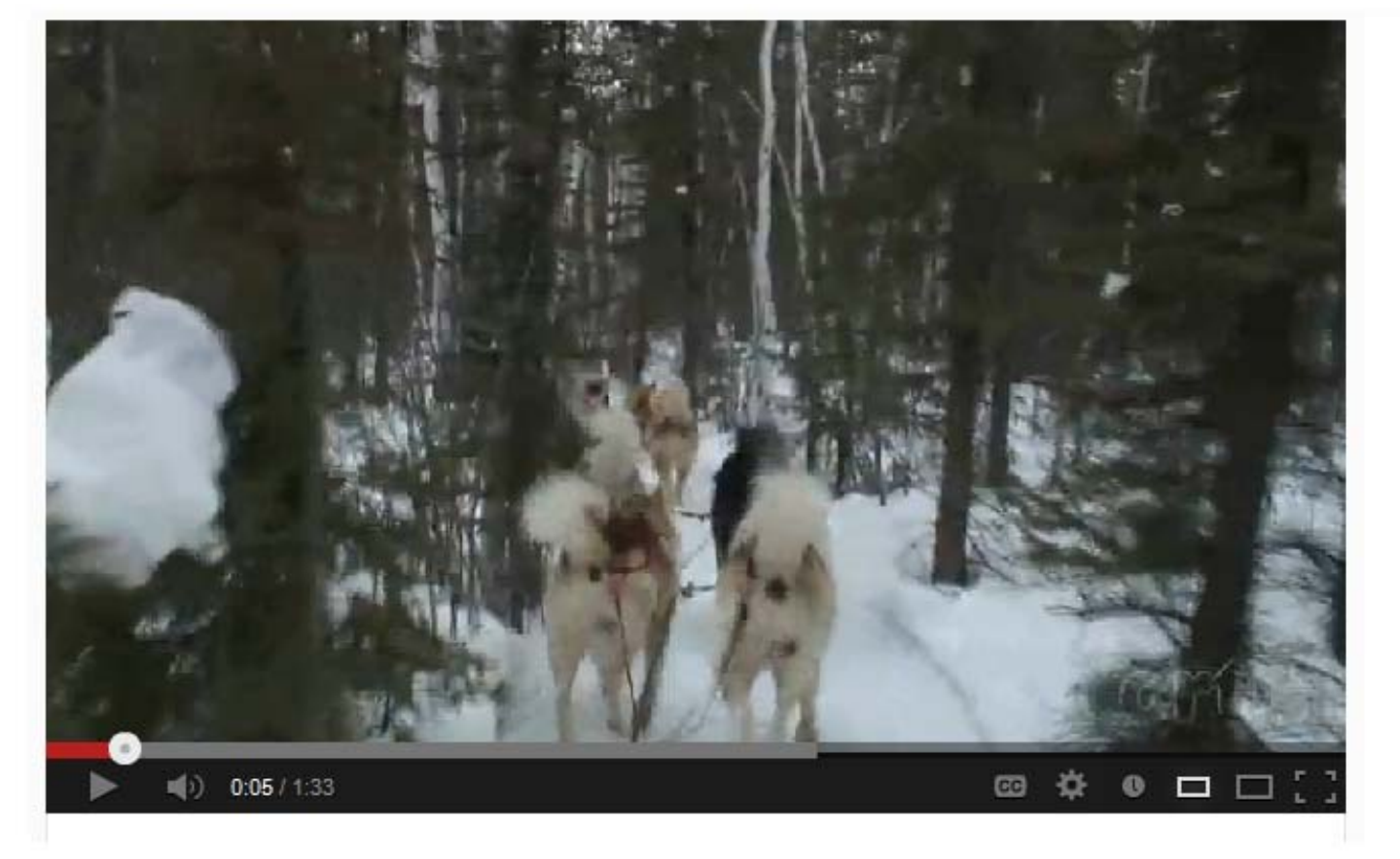

Artifact 2. Narrow Trails in the Arctic National Wildlife Rescue. April, 2006 movie from the trail.

In addition to the video and audio artifacts, participants engage with the experience via numerous other media including weekly trail reports that present the expedition and adventure (Figure 1), a dog blog that presents the expedition through the eyes of one of the participating 
dogs, and collaboration zones where participants can interact in real-time with experts and each other. Other features of the learning environment include web-based video games relating to the issues of inquiry and region of travel, and opportunities for learners to send notes of encouragement to the explorers.

\section{Week 09 Our (Changing) Arctic...}

Date Posted: 4.27 .2009

Location: $66^{\circ} 08^{\prime} \mathrm{N} 65^{\circ} 41^{\prime \prime W}$

Pangnirtung, Nunavut, Canada

Weather Conditions: Sunny blue sky $24^{\circ} \mathrm{F}\left(-4^{\circ} \mathrm{C}\right)$

"My hands smell like seal meat - that's so cool!" Chris bursts out with a chuckle. The grin pretty much hasn't left his face since he and Aaron stepped out of the airplane landing in Pangnirtung on Saturday. Aaron and Chris have arrived, we each have a Pang hat (I) and the sleds are loaded. We are all grinning, Polar Huskies included. It's time to strap on the skis-we are heading out on our Arctic journey!

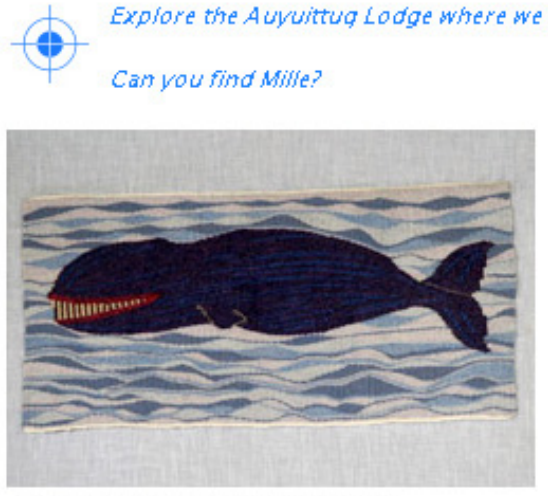

Pang is fämous for its tapestry àt
Watch Anma Etuangat work her loom, weaving a large tapestryl

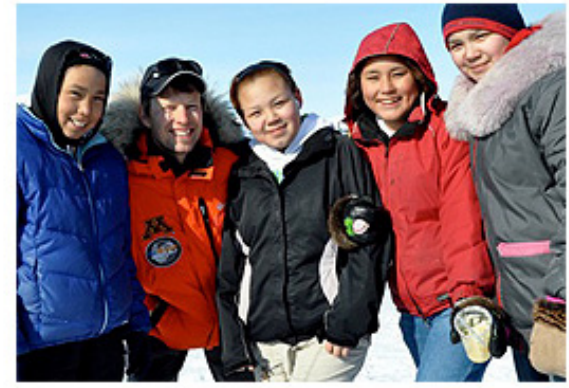

Explore Pangmirtung from the ice on the fiord.

Can vou find the fodge?

"Our Arctic" it reads across the brochure from the Uqqurmiut Centre, the local arts and crafts center here in Pang. And wow! There are so many beautifully woven scarves, the infamous hand crocheted 'Pang hats' and tapestry in brilliant colors made on huge looms-the Arctic comes alive in colors and textures.

In the back of the workshop stands an enormous loom, maybe 20 feet wide ( 5 meters). The next job to be completed on this loom is a huge tapestry to be hung at the Olympic winter Games 2010 in Vancouver. And guess what? We saw a sneak peak of it vesterday!! We walked into what we think must be Nunavut's most famous print shop, simply because of the artists that at times work here. It was pretty quiet in the shop with no one working other than a man sitting with his back towards us working on a computer. However, the man turned out to be none other than Andrew Qappik himself! Andrew is the artist who created the design of Nunavut flag and the government logo with the bear! And now he is working on the tapestry for the Olympics! Yep, we were star struck!

Figure 1. A weekly trail report from the Arctic

Educational expeditions grounded on the Adventure Learning framework have been scarce (Doering, 2006). Yet, the appeal of this approach is demonstrated by (a) research efforts highlighting immersion in authentic practice (Herrington et. al., 2004; Lebow \& Wager, 1994) and (b) worldwide attempts by explorers to actively involve classrooms in their expeditions. Examples of the most recent expeditions that have attempted to engage students in (curriculumguided and adventure-based) distance education approaches include SouthPoleQuest and Polar Bears in a Changing Climate. A short description of the experience of trekking to the South Pole along with a sketch of student participation in one of these projects is provided by Ray Zahab in his 2009 TED talk embedded below (Artifact 3).embedded below (Artifact 3). 


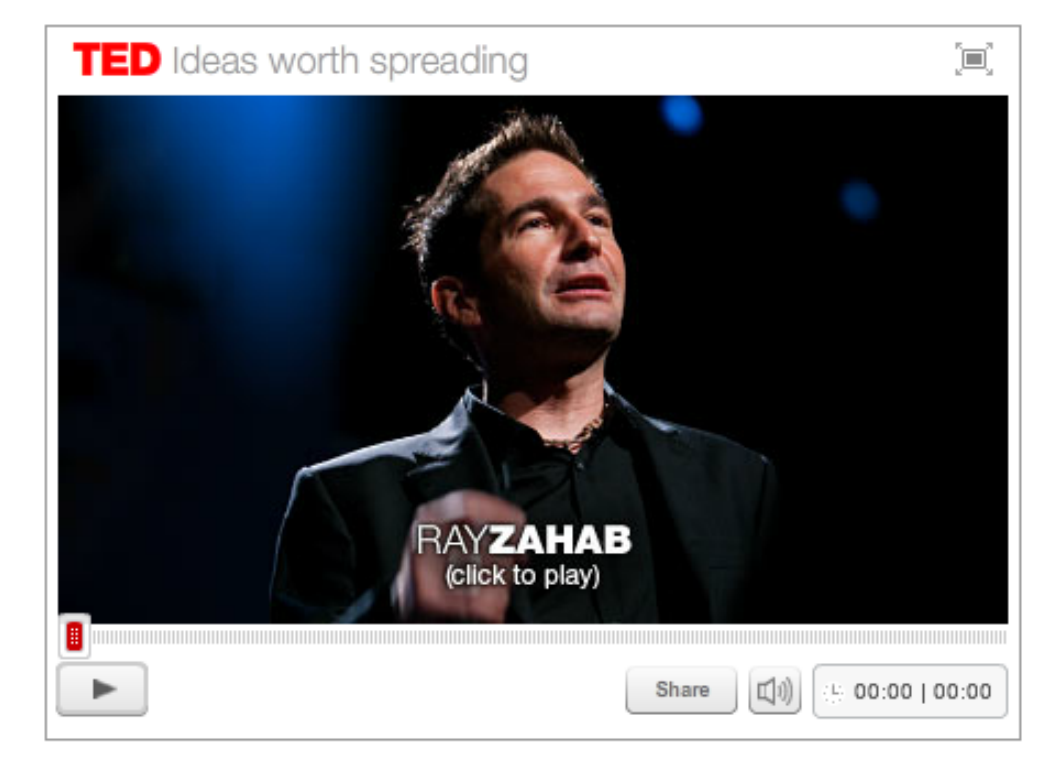

Artifact 3. Ray Zahab Treks to the South Pole

In a recent metasynthesis of the Adventure Learning literature, Veletsianos \& Kleanthous (2009) note that the AL approach to education is engaging and potentially powerful, while being flexible enough to be integrated by teachers in the way that they feel best fits their goals. For example, prior research has noted that a number of students sought to change their parent's driving behaviour after learning about climate change and that a number of parents asked teachers to continue using the AL approach in their classroom. Although the Arctic projects undertaken demonstrate the possibilities and excitement afforded by this approach, research on small-scale Adventure Learning activities within higher education is lacking.

\section{A Higher Education Adventure Learning Activity}

Participants in this activity were thirty face-to-face and distance learning graduate students pursuing a degree in educational technology. Face-to-face students were in their second semester of study, and distance learning students were either in their second or fourth semester of study. The course in which this particular activity took place focused on the foundations and use of emerging technologies for education.

The developed activity was grounded on a set of practical guidelines proposed by the Learning Technologies Collaborative (in press) to guide the design of "mini" Adventure Learning projects (Figure 2). These guidelines were used as the basis for designing the activity, but were also adapted to fit the curricular and pedagogical needs of the course. Specifically, providing opportunities for interaction between learners and experts/professionals was an integral part of the design, influencing how the design guidelines were conceptualized. The design of the learning activity is described below. 


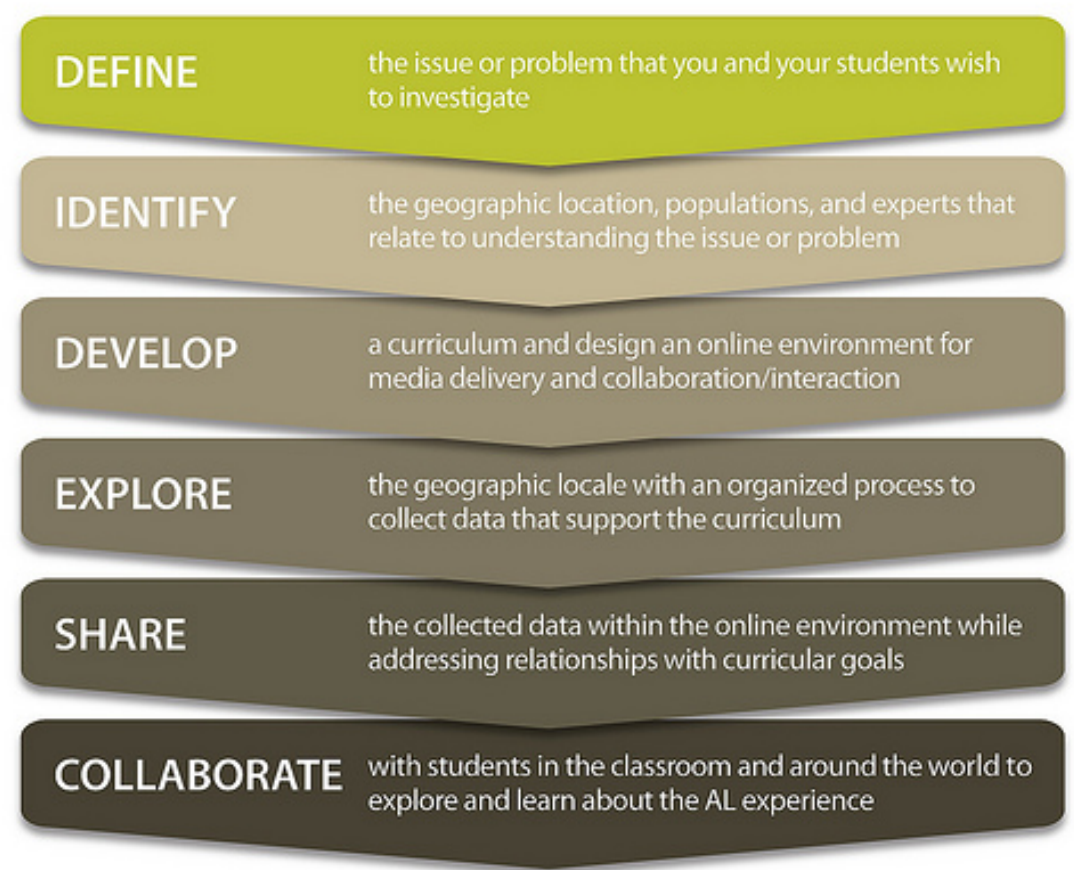

Figure 2. Design and implementation guidelines for "mini" Adventure Learning projects [from The Learning Technologies Collaborative (in press)]

\section{Define}

In this stage, the issue/problem that an instructor wants to investigate is delineated succinctly and clearly. The purpose of the AL activity in this situation was for learners to explore openness in education and, in particular, to critique, discuss, and assess how web technologies have "opened up learning to the point where anyone can learn anything from anyone else at any time” (Bonk, 2009).

\section{Identify}

The second stage of the model calls for identification of the location, populations, and experts that relate to the issue under investigation. The location to be explored is the Internet along with associated Web 2.0 technologies in the context of enabling open and free access to resources, knowledge, and learning. In this activity, the students were the main participants and the instructor of the course was the designer of the activities. The students also interacted with two experts, one of which was the course instructor. The second expert was a Professor of Education with a deep knowledge of the topic under investigation. This person's contribution is further described in the next stage.

\section{Develop}

At this stage, a curriculum and online learning environment are designed. The curriculum in this specific instance was grounded on ideas of scaffolded inquiry (Brown \& Campione, 1994; Reiser, 2004) and situated learning (Lave \& Wenger, 1991). The learners were first asked to individually (a) watch a recorded keynote speech by the identified expert, (b) read a set of relevant papers on the topic, and (c) write two questions that they wanted to ask this individual. Student questions were collected via a web-based form and it was observed that the questions 
fell into four broad themes. The themes and accompanying questions were then sent to the expert who replied to the questions via a video posted on a video-sharing site. Finally, students were asked to watch the expert's reply, respond with their own comments, and discuss the issues that related to the topic of investigation. The process was facilitated by a Wiki that served as the learning environment for this activity.

The Wiki hosted the following:

- background information on the activity (such as resources and papers that the students were asked to read and links to the expert's keynote and personal webpage);

- the students' questions;

- the expert's video reply; and,

- $\quad$ student-instructor and student-student conversations on the topic and videos

\section{Explore}

At the explore stage, learners are asked to investigate the location of interest to collect data supporting the curriculum. Note that while the guidelines call for a "geographic locale," the site for this activity was the Internet and its associated web technologies. This step was modified to involve exploration along with data generation and analysis, rather than data collection. Since location exploration occurred in the prior step, in this step learners were asked to generate their own resources relating to the topic of openness. Specifically, collaborative teams of learners were given 90 minutes to complete the following task:

You are a learning designer working for the University. Your manager has asked you to develop a freely-available online resource that answers the question: What is it like to study for a Master of Arts program at this University? When developing this resource, consider the lessons learned so far.

Importantly, this task allowed flexibility within a real and relevant scenario, while enabling learners to further take an active part in the learning process. Further, the resources developed served as user-generated examples of the topic of investigation, while serving as authentic case studies of openness in the next stages of the learning activity.

\section{Share}

Once the learners developed their resources (e.g., blogs, videos, social networking sites), these were then shared on the online learning environment (i.e. the class Wiki). Both at this point and on the discussion space provided by the wiki, the learners critiqued and discussed the developed resources to reach new understandings relating to the curricular goals identified in the define step. Learners discussed the issue of openness and examined how web technologies have enabled educators to share content, resources, and expertise on the Internet, while at the same time, investigating the structures that hinder free and personalized online learning.

\section{Collaborate}

The collaborate step calls for peer-expert, peer-instructor, and peer-peer collaboration to discuss the experience. This step is the one that, at least in this activity, was dispersed throughout the experience. Collaboration happened at nearly all stages of the activity, as well as at the end of the activity when students discussed their resources with their colleagues. For instance, learners developed online resources in teams and asked questions of each other in relation to their 
resources and wiki postings. Finally, throughout the activity, learners were encouraged and supported to explore ideas and issues relating to openness, technology, digital divides, and online education. Questions discussed included: Are new technologies opening up education? What does openness mean? Who benefits from open resources? What are the implications of openness for organizations (e.g., universities), current practices (e.g., accreditation), and the individual? What are the purposes of education and what is the role of the educator and the university, and how are networked technologies influencing these? What are the difference between knowledge and learning? Is “open education” a goal we should strive towards?

Taken together, these six steps, define the narrative of the experience where the story develops and unfolds over several steps that traverse both face-to-face and online spaces. Importantly, while some elements of the story are known in advance (i.e. the topic of study and the fact that the learners were to interact with the identified expert), a number of aspects are "hidden" from the learners and revealed at appropriate times so as to spark feelings of excitement, anticipation, and unexpectedness (e.g., learners were told to bring cameras, cell phones, laptops, and any other piece of hardware they wanted to use for the explore task that was to be revealed to them during class time). Finally, note that the developed storyline encompasses a beginning (watching the keynote), a middle (e.g., asking questions, developing a resource, receiving feedback), and an ending that brings the experience to closure (sharing the developed resources and discussing any final questions/issues). The idea that learning experiences may encompass a beginning, middle, and end in the same way as narratives is explored by Parrish (2008) who discusses possible ways to view a learning experience based on the learner's "journey" through it and argues that "using narrative as a guiding force for instruction...can be a powerful way to stimulate learning engagement. Like a narrative, effective learning situations will have well established beginnings, middles, and endings that follow the pattern of aesthetic experience and contain the narrative components described above, revealing a necessary struggle to resolve a problematic situation that leads to learning."

\section{The Learning Experience}

The learning experience with respect to this activity was evaluated via (a) web analytics data and (b) an anonymous student questionnaire. In their Framework of Experience, Wilson and Parrish (2009) argue that investigating the learning experience means taking a deep and holistic look into situational and individual qualities of a learning experience. Examples of situational qualities may be the extent to which an experience is compelling or immediate, while an example of an individual quality may be the extent to which a learner is willing to invest mentally and emotionally in the experience in anticipation of future outcomes. Therefore, it is important to note that while the experiences described below are generally positive, one needs to recognize that personal qualities brought in the experience influence its outcomes.

Web analytics refers to "the measurement, collection, analysis, and reporting of Internet data for the purpose of understanding and optimizing Web usage” (Web Analytics Association, 2005). Data collection through web analytics is a powerful method to track learner behaviors and activities, and is an approach that is poised to influence the design and evaluation of distance education (Rogers, McEwen, \& Pond, in press). In this investigation, I used Google Analytics as the web analytics application because of its extensive reporting capabilities and ease of integration with the online learning environment hosting the Adventure Learning activity. 
Comparative web analytics data indicate that this activity was popular: The Wiki page hosting the Adventure Learning activity was the third most visited page out of all the weekly session pages (the Learning Platforms page and the Web 2.0 \& Co-construction of knowledge pages being the top two). Average time spent on the wiki across all pages was 2 minutes and 19 seconds, while the average time spent on the Adventure Learning page was 4 minutes and 5 seconds (in comparison, the average time spent on the page describing student assignments was 3 minutes and 44 seconds). Note that even though the AL page included an embedded video of the expert's response that may have influenced time spent on the page, numerous other pages throughout the course also included embedded videos of similar length.

Overall, approximately $87 \%$ of respondents agreed or strongly agreed with the statement that they imagined themselves in the position of a learning technologist. In addition, $80 \%$ of respondents noted that the activity has been one of the most fun times they've had at university, and $80 \%$ of them liked the challenge presented to them by the activity. Importantly, learners noted that the activity was motivating and challenging as it presented an open-ended and complex issue. Students noted that the activity "encouraged a lot of thinking and reflection" while also demonstrating an understanding of some of the complexities involved:

"Working with a team to create an open teaching resource was fun as a procedure but I don't know if the material we produced will be used as an open teaching resource because not really everyone can find it.”

"This [the idea of the internet opening education to everyone] maybe is a bit too idealistic" and "the world is not actually open as it claimed."

The majority of responses to the survey questions with regards to the learning activity were positive, with students describing their experience as "active," "motivating," "innovative," "inspiring," "fun," “enlightening," and "fascinating.” One student summarized these feelings succinctly: "It was an interesting experience, educational but at the same entertaining. It was really enjoyable." The negative feelings towards the activity related to the limited amount of time the students had to complete the exercise.

Students also noted that the activity was quite different from what they have been used to in their undergraduate and graduate careers. One student wrote that this activity was "more engaging and motivating than what I was used to," while another student clarified that the reason may be because "we are getting tired of listening to lectures. We need more of these activities that we just 'do' things and we are active." Similarly, other students stated that "[the activity] made me walk the talk [of using emerging technologies in education]," and "actually produce something in a short period of time using emerging technologies. I am not sure if a class can be more engaging than that.” These feelings were summarized by yet another student who stated that, "it was unique in the sense of getting to know [the expert] and what he supports online, therefore getting to know the possibilities of online education...also the fact that we had to work with different kind[s] of modern technologies and be actively involved in learning, [becoming] critical thinkers and not just passively accepting new knowledge.”

Finally, it is also important to address the qualities that individuals brought to the learning experience. While a few learners highlighted the situational aspects of their experience (e.g., "We need more of these activities that we just 'do' things and we are active”), engagement also depends on individual qualities. For instance, Figure 3 shows visits from a city in which one of the distance students resided during the teaching of this course. 


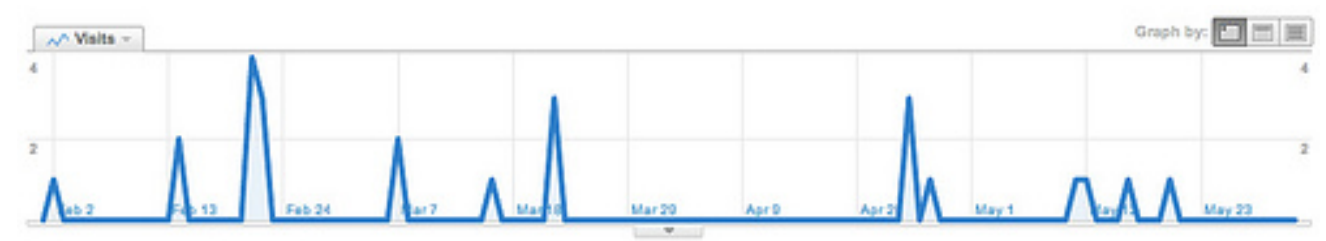

This city sent 24 visits

Figure 3. One student's visits to the Wiki over the duration of the course

This student visited the Wiki 24 times (on 11 different days). The graph above indicates that this student's learning experience was sporadic and fragmented. The student visited the site once during this learning activity and did not participate in the discussion with the expert. While this student may have been unable to participate in this specific activity for a number of reasons relating to pursuing a degree at a distance (e.g., work schedule), the overall activity shown on the graph above indicates a low engagement overall. As a comparison, two students who resided in a different city visited the Wiki 249 times (or, about 125 times each), and one student who resided in yet another city visited the Wiki 147 times (Figure 4).

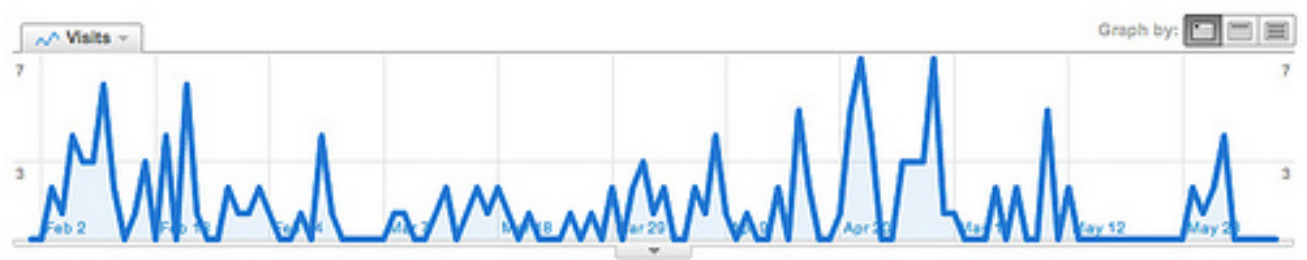

This city sent 147 visits

Figure 4. A second student's visits to the Wiki over the duration of the course

Finally, it is important to note one additional attribute of the graphs that highlights the different levels of motivation and initiative that existed between the students: The University was closed for the Easter holidays in the period between March and April. Prior to this, students were reminded that this period would have been a good time to work on their final assignment since they were not assigned any other tasks. The graphs show that the student depicted in Figure 3 did not visit the Wiki at all during that time (flat line between March and April) while the student depicted in Figure 4 visited the Wiki multiple times (further analysis of the logs indicated that the student in Figure 4 also visited the page describing the final assignment).

To summarize, overall, the student experience in the Adventure Learning project can be described as engaging and appealing. Learners cherished the situational qualities of the learning experience, but individual engagement with the learning activity varied. They appreciated the practical and participatory nature of the experience, and valued its active and personalized aspects. Evidence to the personally meaningful and compelling learning experience is the fact that at the end of the activity, students, on their own volition and discretion, invited friends from outside the course to participate in and use their developed resources. The desire to share university work with individuals that are close to the students (e.g., family and friends) reveals the value that the students placed on this experience.

\section{Implications for Research and Practice}

Student comments shed light on the situational qualities of the learning experience allowing us to draw implications for the design of small-scale Adventure Learning projects. Specifically, this 
investigation highlighted the links between powerful pedagogy, social media affordances, creative curricula, authentic practice, and narrative. An informed understanding and appreciation of how these five issues relate to each other can enable practitioners, researchers, and designers to harness the seamless integration of technology in education via the Adventure Learning approach.

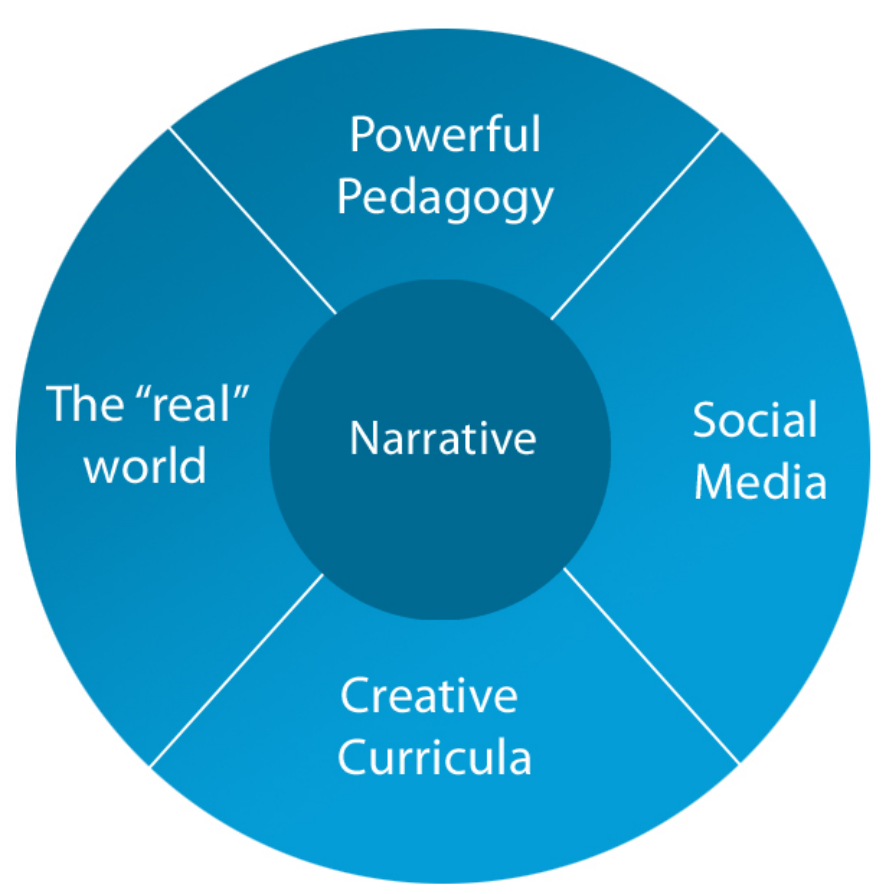

Figure 5. Focal points for seamless technology integration

\section{The "Real World," Authentic Learning, and Social Media}

Learners are interested and intrigued by the real world, the world that exists beyond the classroom walls, and not in simplified representations or textbook examples of the world presented in the classroom. Additionally, student interest and curiosity relating to the real world is not limited to K-12 settings: the learning activity and it's associated outcomes discussed above demonstrate that curiosity and interest in the real-world exist and can be utilized in highereducation learning endeavours. Learners enjoyed engaging with a topic in a real-world context, asking questions to a real-world expert, and developing authentic materials for possible use.

While the simple understanding that learners are intrigued by the real world has wide implications for education in general, I will focus on technology-enhanced learning in particular. For example, the realization that students are intrigued by the real world, coupled with the fact that modern technology flattens the world both in distance and access to networks (e.g., informal networks of professionals), allows us to rethink the role of technology in education. In the same way that the GoNorth! students in the Arctic regions of the world present their day-to-day life to and discuss whaling methods with participants worldwide, students can collaborate with any willing expert. Examples abound, within numerous learning contexts:

- $\quad$ students enrolled in a formal program of study at the graduate level (as the course described by Couros (2009) and the one reported in this paper show); 
- $\quad$ students enrolled at the K-12 level (e.g., see this collaboration between 7th graders and Professor Lawrence Lessig relating to copyright law); and,

- learners who are engaging in informal learning (see for example, http://www.conversations.net and the site's interview series on the impact of the Internet on society)

Further, technology, and social media in particular, extend beyond enabling expertlearner collaboration. Participation in networks of practice can take many forms: Students can participate in virtual explorations of building sites to learn mathematics, archaeological areas to learn history, drainage basins to explore ecological processes, and court deliberations to investigate the application of law. Students who are investigating a career choice can follow the day-to-day happenings of artists, bankers, brokers, video game programmers, nurses, and any other profession imaginable effortlessly and synchronously. Importantly, Web 2.0 technologies have diminished conversational obstacles and made interaction between participants more feasible, cost-effective, and manageable. Take the example of a group of students learning about the craft of carpentry and following the day-to-day activities of a carpenter. The carpenter could keep a blog where s/he could post reflections of the day's activities along with other relevant information such as images of his/her designs and video of his/her ongoing activity. The images and video could invite feedback and scaffolded inquiry via a number of social tools (e.g., Voicethread).

Furthermore, recent developments on the web have allowed networked participants to be alerted of news and messages as they are published (i.e. in real-time), and these developments may allow greater immersion in a learning experience. For instance, medical school students can participate in a learning adventure of what it means to be a doctor by subscribing to receive a doctor's microblogging feed via text alerts on their mobile phones. In this way, when the doctor is called in for an emergency in the early hours of the morning, for example, the learners can be alerted of the event, thus gaining vicarious, but immediate and first-hand, experience of the profession. The ability to exchange real-time messages can bridge physical and virtual experiences, and relay a sense of immediacy and connectedness that may heighten the learning experience.

\section{Creative Curricula and Powerful Pedagogy}

Implicit in the discussion of authentic experiences that are mediated by social media and that bridge in- and out-of-classroom practices, is the idea that educators need to rethink curricula and pedagogy. Importantly, social media use and participation in real-world experiences do not guarantee, or even foster, engaging learning experiences. For instance, what is the value of field trips to historical monuments, museums, archaeological areas, or any other out-of-classroom spaces, when the students are lectured to or are told to "explore" under the premise of "constructing knowledge" without any scaffolded guidance? These two extremes are highly problematic:

- Knowledge dissemination in the form of information delivery fosters passive, dispassionate, and noncritical learners (Freire, 1970), along with poor learning experiences. 
- "Pure" discovery-based (or, completely-unguided) methods are ineffective with individuals who are not self-directed or with those who do not have the prerequisite background knowledge.

Returning to our Adventure Learning example, a visit to a (virtual or physical) space needs careful examination and development of a creative curriculum, along with support from inquiry- or problem-based pedagogy that is truly guided or scaffolded (Hmelo-Silver, Duncan, \& Chinn, 2007). Such pedagogy should strive to support and extend learners' thinking, skills, and learning beyond their current levels, in what Vygotsky (1978) called the Zone of Proximal Development (ZPD). Importantly, a learner's thinking and knowledge can be expanded via interactions with the instructor, other experts (see previous section), other students/colleagues, and mediating artifacts (e.g., museum objects or virtual objects).

The activity described in this paper sought to engage learners in an active exploration of "openness" in a situated learning fashion. In particular, learners investigated openness by watching a freely available keynote, engaging in conversations with experts and colleagues, and developing open educational resources. During these activities, learners' thinking was supported and extended by interactions with experts and each other, enabling them to investigate diverse points of view and critically evaluate "openness." For instance, in their questions to the expert, a number of learners questioned the idea of open educational resources representing free learning, and sought explanation on how openness relates to digital divides, "My question is about the digital divide... What about those who have no hope and for whom their respective governments are caught in a hegemonic stronghold that is in the latter's interest to perpetuate? How do we deal with the complex issues of human behaviour rooted in cultural, social, and political hegemonic struggles and tensions?" and "How does openness provide for the marginalized communities to avoid multiplying the effects of [the] digital divide?"

One of the premises of this paper therefore is that learning experiences need to be enhanced in ways that invite participation, inquiry, and immersion in authentic practice. One example that highlights these ideas comes from Doering et. al. (2009) who describe an online learning environment in which real geographic problems are presented to learners. In this environment, learners take on the role of geographers that solve authentic problems based on real-world data, and are invited to present solutions to real organizations. The problems are relevant and contemporary, and learners are asked to use tools employed by real geographers to solve real problems. For example, one module asks learners to decide where would be the best location to build a new football stadium given data relating to income levels, population density, competing football teams, etc.

\section{Narrative}

Even though the ideas of narrative and storytelling within technology-enhanced learning and instructional endeavours are still emerging forms of practice and research (Andrews, Hull, \& Donahue, 2009; Brna \& Luckin, 2008; Hokanson \& Fraher, 2008), narratives are pervasive in our everyday lives as they are embedded in human cultures and oral tradition. A narrative structure brings together the learning experience and its diverse activities under a unified purpose, establishing continuity and coherence to learning experiences that span across multiple media and information spaces (Hazel, 2008). In the example of the Adventure Learning project described above, both the activity and learners' participation in it reside in multiple spaces (e.g., wiki, website hosting the expert's keynote, face-to-face meetings). Navigating these spaces can 
be both confusing and difficult. Structuring the experience in terms of a narrative however, establishes a sequence and a storyline, and enables the multiple pieces of the experience to form a uniform whole. Additionally, narratives serve purposes beyond the establishment of continuity and coherence (Hokanson \& Fraher, 2008) as they allow (and encourage) creativity and imagination in learning design, enabling effective, enjoyable, and entertaining learning experiences. In the case of the activity described in this paper, the "story of openness" could have been told in multiple ways: It could have been presented as a narrative of hope, a narrative of opening up access to everyone regardless of socio-economic status; or, the story could have taken a narrative of liberating learning from institutional control. The way a story is told is important: plots give stories their power and enable conveying of meaning, which is part of the reason that narrative and storytelling have been proposed as viable approaches to teaching (Kieran, 1985). In this situation, the story of openness took on a narrative of possibilities: the possibility of learning from a well-known expert, the possibility of the expert answering learner questions, and the possibility of others discovering the open educational resources that students developed. The results discussed above, highlight the exciting, engaging, and meaningful aspects of these possibilities.

\section{Conclusion}

In this paper, I presented a small-scale Adventure Learning activity designed within a higher education curriculum. Results from the implementation of this activity are promising and highlight the viability of Adventure Learning in the context of (a) small-scale projects and (b) higher education settings. To facilitate the development of small-scale AL projects in higher education (and to enhance higher education practice) we need to rethink education in terms of pedagogy, social media, creative curricula, authentic learning, and narrative. Rather than thinking about products (e.g., courses contained within learning management systems), we need to think of experiences, engagement, and interaction, and view ourselves as designers of learning experiences. Such experiences should foster participation and interaction, be situated in authentic practice, and be supported by creatively designed pedagogies and curricula. Future advances in small-scale Adventure Learning implementations can provide valuable information to enhance educational practice and inform implementations that cross disciplinary lines. Future research should investigate how to effectively prepare educators in designing their own Adventure Learning projects, examine the extent to which adventure learning projects enable similar outcomes, explore how to best scale such projects, and further delineate how to design engaging and powerful adventure learning experiences.

The Adventure Learning activity described in this paper represents a model of education that has the potential to (a) resonate with designers and academics, while (b) transforming formal practice in higher education institutions. We need to stop positioning our hopes of improving education on one item (most usually technology), and envision integrative approaches to learning that not only solve problems but also change the nature of education and reconsider the kinds of experiences that we offer to learners. To do so, we need to reflect on the purposes of education and review the role of the physical classroom in the world. 


\section{References}

Allen, E., \& Seaman, J. (2010). Learning on demand. Online Education in the United States, 2009. Needham: Sloan Center for Online Education. Retrieved on March 18, 2010 from http://www.sloan-c.org/publications/survey/pdf/learningondemand.pdf

Andrews, D., Hull, T., \& Donahue, J. (2009). Storytelling as an instructional method: Definitions and research questions. Interdisciplinary Journal of Problem-based Learning, 3(2). Online serial available at http://docs.lib.purdue.edu/ijpbl/vol3/iss2/3

Bednarz, S.W., \& van der Schee, J. (2006). Europe and the United States: The implementation of geographic information systems in secondary education in two contexts. Technology, Pedagogy, and Education, 15(2), 191-205.

Brna, P., \& Luckin, R. (2008). Narrative and interactive learning environments. Interactive Learning Environments, 16(3), 195-197.

Brown, A. L., \& Campione, J. C. (1994). Guided discovery in a community of learners. In K. McGilly (Ed.), Classroom lessons: Integrating cognitive theory and classroom practice (pp. 229-270). Cambridge, MA: MIT Press.

Couros, A. (2009). Open, connected, social - implications for educational design. Campus-Wide Information Systems, 26(3), 232-239.

Cuban, L. (2001). Oversold and underused: Computers in the classroom. Cambridge, MA: Harvard University Press.

Doering, A. (2006). Adventure learning: Transformative hybrid online education. Distance Education, 27(2), 197-215.

Doering, A., Scharber, C., Miller, C., \& Veletsianos, G. (2009). GeoThentic: Designing and assessing with technology, pedagogy, and content knowledge. Contemporary Issues in Technology and Teacher Education [Online serial], 9(3). Retrieved from http:/www.citejournal.org/vol9/iss3/socialstudies/article1.cfm

Doering, A., \& Veletsianos, G. (2008). Hybrid online education: Identifying integration models using adventure learning. Journal of Research on Technology in Education, 41(1), 101-119.

Freire, P. (1970). Pedagogy of the oppressed. New York: Continuum.

Hazel, P. (2008). Toward a narrative pedagogy for interactive learning environments. Interactive Learning Environments, 16(3), 199-213.

Herrington, J., Reeves, T., Oliver, R., \& Woo, Y. (2004). Designing authentic activities in webbased courses. Journal of Computing in Higher Education, 16(1), 3-29.

Hmelo-Silver, C. E., Duncan, R. G., \& Chinn, C. A. (2007). Scaffolding and achievement in problem-based and inquiry learning: A response to Kirschner, Sweller, and Clark (2006). Educational Psychologist, 42(2), 99-107.

Hokanson, B., \& Fraher, R. (2008). Narrative structure, myth, and cognition for instructional design. Educational Technology, 48(1), 27-32.

Johnson, D. W., \& Johnson, R. T. (2004). Cooperation and the use of technology. In D. H. Jonassen (Ed.), The Handbook of research for educational communications and technology (pp. 785-811). Mahwah, NJ: Lawrence Erlbaum Associates. 
Egan, K. (1985). Teaching as story-telling: A non-mechanistic approach to planning teaching. Journal of Curriculum Studies, 17(4), 397-406.

Lave, J., \& Wenger, E. (1991). Situated learning: Legitimate peripheral participation. Cambridge: University of Cambridge Press.

Lebow, D., \& Wager, D. (1994). Authentic activities as a model for appropriate learning activity: Implications for emerging instructional technologies. Canadian Journal of Educational Communication, 20(3), 231-44.

Parrish, P. (2008). Plotting a Learning Experience. In L. Botturi \& T. Stubbs (Eds.), Handbook of visual languages for instructional design: Theories and practices (pp. 91-111). Hershey, PA: Information Science Reference.

Parrish, P., \& Wilson, B., (2009). A design and research framework for learning experience. Working paper presented at: The AECT 2008 conference. Retrieved from http://homes.comet.ucar.edu/ pparrish/papers/ExperienceFramework13.doc

Reiser, B. J. (2004). Scaffolding complex learning: The mechanisms of structuring and problematizing student work. Journal of the Learning Sciences, 13(3), 273-304.

Rogers, C., McEwen, M., \& Pond, S. (in press). The use of web analytics in the design and evaluation of distance education. In Veletsianos, G. (Ed.), Emerging technologies in distance education. Edmonton, AB: Athabasca University Press.

Schrum, L., Thompson, A., Maddux, C., Sprague, D., Bull, G., \& Bell, L. (2007). Editorial: Research on the effectiveness of technology in schools: The roles of pedagogy and content. Contemporary Issues in Technology and Teacher Education [Online serial], 7(1). Available: http://www.citejournal.org/vol7/iss1/editorial/article1.cfm

The Learning Technologies Collaborative (in press). "Emerging”: A re-conceptualization of contemporary technology design and integration. Using emerging technologies in distance education. Edmonton, AB: Athabasca University Press.

Van Hover, S. D., Berson, M. J., Bolick, C. M., \& Swan, K. O. (2006). Implications of ubiquitous computing for the social studies curriculum (Republished). Contemporary Issues in Technology and Teacher Education [Online serial], 6(2). Available: http://www.citejournal.org/vol6/iss2/socialstudies/article3.cfm

Veletsianos, G., \& Doering, A. (2010). Long-term student experiences in a hybrid, open-ended and problem based Adventure Learning program. Australasian Journal of Educational Technology, 26(2), 280-296. Available: http://www.ascilite.org.au/ajet/ajet26/veletsianos.pdf

Veletsianos, G., \& Kleanthous, I. (2009). A review of adventure learning. The International Review Of Research In Open And Distance Learning, 10(6), 84-105. Retrieved from http://www.irrodl.org/index.php/irrodl/article/view/755

Vygotsky, L.S. (1962). Thought and language. Cambridge, MA: MIT Press.

Vygotsky, L.S. (1978). Mind and society: The development of higher psychological processes. Cambridge, MA: Harvard University Press.

Wilson, B., Parrish, P., \& Veletsianos, G. (2008). Raising the bar for instructional outcomes: Towards transformative learning experiences. Educational Technology, 48(3), 39-44. 